\title{
HUBUNGAN KARAKTERISTIK DENGAN ASPIRASI BEKERJA DALAM BIDANG AGROINDUSTRI PERIKANAN PADA PEMUDA PEDESAAN DI DESA PUGER WETAN KECAMATAN PUGER KABUPATEN JEMBER
}

\author{
Oleh: \\ MOH.SHIDIQ SHOFI A *), RATIH PUSPITORINI YEKTI AMBARKAHI dan MUKSIN **)
}

\begin{abstract}
ABSTRAK
Penelitian ini bertujuan untuk menjelaskan seberapa kuat hubungan antara karakteristik individu dan karakteristik lingkungan dengan aspirasi pada pemuda yang bekerja di agroindustri perikanan di Desa Puger Wetan, Kecamatan Puger, Kabupaten Jember. Pada penelitian ini, rancangan penelitian yang digunakan adalah jenis penelitian survai (survey research), dalam penelitian ini sebagai unit analisisnya adalah pemuda di desa puger wetan yang berjumlah 34 pemuda. Informasi atau data tentang karakteristik individu, karakteristik lingkungan dan aspirasi diperoleh berdasarkan pandangan, tanggapan, dan persepsi dari pemuda. Penelitian ini menggunakan metode sampel yang representatif, cara pengambilan sampel menggunakan proporsional random dengan cara diundi, dimana pada daerah penelitian terdapat empat agroidustri perikanan dengan jumlah pemuda yang berbeda-beda. Metode analisis yang digunakan adalah analisis korelasi.

Variabel bebas dalam penelitian ini adalah Karakteristik individu dan Karakteristik lingkungan. Sedangkan variabel terikatnya adalah Aspirasi.

Berdasarkan pengujian koefisien korelasi Asosiasi Eta Terdapat hubungan yang nyata positif antara status jenis kelamin dengan aspirasi, pengujian koefisien korelasi Asosiasi Eta Terdapat hubungan yang nyata positif antara status perkawinan dengan aspirasi. Berdasarkan hasil analisis koefisien korelasi Spearman's rho Tidak terdapat hubungan yang nyata antara usia dengan aspirasi dan Tidak terdapat hubungan yang nyata antara tingkat pendidikan dengan aspirasi. Sedangkan berdasarkan analisis korelasi Pearson Product Moment Terdapat hubungan yang nyata positif antara karakteristik lingkungan dengan aspirasi.
\end{abstract}

Kata kunci : Karakteristik individu, Karakteristik lingkungan, Aspirasi 



\section{PENDAHULUAN}

Secara geografis Kabupaten Jember mempunyai wilayah laut yang cukup luas dan membentang di sepanjang Pantai Selatan Jawa atau Samudera Indonesia dengan panjang pantai kurang lebih $170 \mathrm{~km}$. Sedang luas perairan Jember yang termasuk ZEE (Zona Ekonomi Ekslusif) kurang lebih 8.338,5 km2, dengan potensi lestari sebesar 40.000 ton per tahun. Namun potensi yang sangat besar tersebut, sejauh ini belum dikelola dan dimanfaatkan secara maksimal atau sekitar $20 \%$. Jumlah produksi ikan di kawasan pantai di Jember setiap tahun sekitar $6.315,22$ ton dengan nilai produksi sebesar Rp 16.334.583.240. Produksi tersebut termasuk ikan kering 1.201,30 ton, ikan pindang $1.824,80$ ton dan ikan asapan 204,10 ton. Disamping itu, Kabupaten Jember masih memiliki potensi yang berkualitas ekspor dan yang masih dibudidayakan. Potensi berkualitas ekspor tersebut adalah "Terasi" yang telah dikemas serta siap masak/saji (Website Resmi Kabupaten Jember, 2008).

Puger merupakan salah satu kecamatan di Kabupaten Jember dengan luas wilayah 7.357 Ha, yang terdiri dari 12 desa. Dengan jumlah penduduk 104.568 jiwa, sebagian besar penduduknya berprofesi sebagai nelayan yaitu sekitar 5.649 jiwa. Puger wetan merupakan salah satu dari 12 kelurahan di Kecamatan Puger yang $67.63 \%$ penduduknya bermata pencaharian berprofesi sebagai nelayan. Letak geografis puger wetan yang berhadapan langsung dengan samudera Indonesia membuat sebagian besar merupakan rumah tangga nelayan. Kelurahan puger wetan juga dikenal dengan sektor industri pengolahan perikanan dengan nilai total produksi 3.735.000, sedangkan yang lainnya seperti sebagai ibu rumah tangga istri nelayan dan pedagang ikan. Jumlah Pemuda yang berusia 15-24 tahun yang bekerja di agroindustri perikanan di Desa Puger Wetan untuk industri perikanan terasi di 24 tempat sebanyak 46 pemuda, kerupuk ikan sebanyak 12 tempat terdapat 34 pemuda, ikan kering sebanyak 21 tempat terdapat 39 pemuda, pemindangan sebanyak 31 tempat terdapat 53 pemuda (BPS Kecamatan puger, 2009).

Sejalan dengan arah pembangunan pemerintah, peran pemerintah adalah mempertajam arah pembangunan untuk rakyat melalui penguatan kelembagaan pembangunan, baik kelembagaan masyarakat nelayan maupun kelembagaan Koperasi-UKM. Penguatan kelembagaan pembangunan agroindustri dapat dilakukan melalui pembangunan partisipatif untuk mengembangkan kapasitas pemuda dan berkembangnya kemampuan aparat dalam menjalankan fungsi lembaga pemerintah yang berorientasi pada kepentingan masyarakat. Sedangkan Fenomena yang terjadi di kawasan desa puger wetan, yaitu menyangkut permasalahan untuk dijadikan sebagai suatu bahan kajian yang insentif, implikasinya adalah hubungan karakteristik dengan aspirasi bekerja pemuda tidak hanya dapat meningkatkan pendapatan keluarga nelayan namun diharapkan mampu menambah argoindustri perikanan dan mengurangi kecenderungan perpindahan tenaga kerja yang berlebihan dari desa ke kota, termasuk menghasilkan produk sesuai karakteristik wilayah sehingga dapat memiliki akar yang lebih kuat pada kegiatan ekonomi pedesaan (Djoko Soejono, 2004)

Karakteristik pemuda dari segi psikologi Ausubel (1965) dalam Koners dan Rahayu (2006) memilah status, yaitu bila orang dewasa disebut dengan status primer, artinya status ini diperoleh berdasarkan kemampuan dan usaha sendiri. Status anak, adalah status diperoleh (derved), yaitu tergantung atas pemberian dari orang tua atau masyarakat. Remaja berada pada status interim yakni memiliki ketergantungan pada orang tua dan masyarakat disatu sisi, akan tetapi sisi yang lain remaja berusaha untuk terus melepaskan ketergantungan tersebut, dengan mencari kebutuhan-kebutuhan psikisnya, usaha tersebut yang membuat dia menjadi lebih prestise. Peranan para orang tua menjadi sangat penting untuk mengarahkan dan memberikan kesadaran yang lebih bijak dan arif, lingkungan masyarakat terus berupaya mendukung memberikan apresiasi, ruang komunikasi, membangun hubungan interpersonal yang baik, dan institusi pendidikan.

Aspirasi merupakan harapan atau keinginan yang sungguh-sungguh untuk mencapai sesuatu, dan keinginan tersebut diiringi oleh usaha tertentu, maka dapat disimpulkan bahwa aspirasi mencakup tiga unsur yaitu hasil, usaha, dan penghargaan. Dengan demikian, yang dimaksudkan dengan aspirasi pada dasarnya mencakup tiga unsur karakteristik (aspek), yaitu: (a) harapan atau keinginan, (b) usaha yang dilakukan untuk keinginan itu, dan (c) penghargaan terhadap pekerjaan tersebut (Sarwono 2002).

Berdasarkan uraian latar belakang masalah di atas, terdapat rumusan masalah penelitian sebagai berikut:

1. Adakah hubungan karakteristik individu dengan aspirasi pada pemuda yang bekerja di agroindustri perikanan Desa Puger Wetan, Kecamatan Puger, Kabupaten Jember?

2. Adakah hubungan karakteristik lingkungan dengan aspirasi pada pemuda yang bekerja di agroindustri perikanan Desa Puger Wetan, Kecamatan Puger, Kabupaten Jember? 


\section{METODE PENELITIAN}

Rancangan penelitian yang digunakan dalam penelitian ini menggunakan rancangan penelitian survai. Penelitian survai merupakan penelitian yang mengambil sampel dari populasi dengan menggunakan kuesioner sebagai alat pengumpulan data yang pokok di lapangan (Singarimbun dan Effendi, 1995).

Populasi adalah wilayah generalisasi terdiri atas objek atau subyek yang mempunyai kualitas dan karakteristik tertentu yang ditetapkan oleh peneliti untuk dipelajari dan ditarik kesimpulannya (Sugiyono, 2003). Berdasarkan komposisi jumlah Pemuda usia (15-24) tahun yang bekerja di agroindustri perikanan di Desa Puger Wetan, populasinya berjumlah 172 pemuda. Metode pengambilan sampel menggunakan proporsional random dengan cara diundi (Sugiyono, 2007) dengan perhitungan sebagai berikut:

$\mathrm{n}_{1}=$<smiles>N#[W]</smiles>

Dimana:

$\mathrm{n}_{1} \quad$ = banyaknya sampel di setiap kelas

$\mathrm{n} \quad$ = banyaknya populasi di setiap kelas

$\mathrm{N}$ = banyaknya populasi seluruh kelas

$\mathrm{N}_{1} \quad$ = banyaknya sampel penelitian

Sampel yang digunakan dalam penelitian ini adalah $20 \%$ dari jumlah populasi yaitu 34 pemuda. Hal tersebut sesuai dengan pendapat (Arikunto, S. 2006) dimana jika jumlah subyeknya besar dapat diambil antara $10-15 \%$ atau $20-25 \%$ atau lebih.

Berdasarkan pada kerangka konseptual, variabel didalam penelitian ini dapat di klasifikasikan sebagai berikut:

1. Variabel Bebas (independent variable) adalah variabel yang memiliki hubungan dengan Variabel terikat (dependent variable)

- Karakteristik Individu

a. Jenis kelamin $\left(\mathrm{X}_{1}\right)$

b. Status perkawinan $\left(\mathrm{X}_{2}\right)$

c. Usia $\left(\mathrm{X}_{3}\right)$

d. Tingkat pendidikan $\left(\mathrm{X}_{4}\right)$

- Karakteristik Lingkungan $\left(\mathrm{X}_{5}\right)$

2. Variabel terikat (dependent variable) variabel yang memiliki hubungan dengan Variabel Bebas (independent variable)

- Aspirasi

Sebelum penyebaran kuesioner pada responden dilakukan uji validitas dan reliabilitas terlebih dahulu untuk menguji kelayakan isi dari pertanyaan yang diajukan kepada responden.
Dalam survai uji validitas dilakukan dengan mengkorelasikan skor setiap item dengan total skor. Item pertanyaan yang mempunyai korelasi positif dengan total skor serta korelasinya tinggi, menunjukan bahwa item tersebut mempunyai validitas tinggi pula dimana $r \geq 0,30$. Oleh karena itu jika $r<0,30$ maka butir dalam instrumen tersebut kurang valid (Masrun, 1979 dalam Sugiyono, 2003). Pengujian dilakukan menggunakan korelasi pearson product moment guna melihat konsistensi jawaban pertanyaan, dengan rumus (Sugiyono, 2003) sebagai berikut: 
Dimana:

$$
r_{x y}=\frac{n \sum x y-\left(\sum x\right)\left(\sum y\right)}{\sqrt{\left[\left\{n \sum x^{2}-\left(\sum x\right)^{2}\right\}\left\{n \sum y^{2}-\left(\sum y\right)^{2}\right\}\right]}}
$$

$\mathrm{r}_{\mathrm{xy}} \quad=$ korelasi product moment

$\mathrm{n} \quad=$ jumlah responden

$\mathrm{x}=$ jumlah skor tiap pertanyaan

$\mathrm{y} \quad=$ jumlah skor total

Berdasarkan analisis, semua item pertanyaan memiliki nilai $r \geq 0,30$ dengan kriteria validitas tersebut maka instrumen penelitian dinyatakan valid.

Uji Reliabilitas adalah sebuah indeks yang menunjukkan sejauh mana suatu alat pengukur dapat dipercaya atau diandalkan (Singarimbun dan Effendi, 1995). Menurut Nunnaly (1996) Kutipan Imam Ghozali (2001) Croanbach's alpha suatu konstruk atau variabel dikatakan andal (reliabel) jika memberikan nilai croanbach's $>0.60$. Teknik yang digunakan dalam pengukuran reabilitas adalah tehnik Cronbach, (Umar, H. 2002) dengan rumus yang digunakan sebagai berikut:

$\mathrm{r}_{11}=\left(\frac{\mathrm{K}}{\mathrm{K}-1}\right)\left(\frac{\mathrm{T}-\sum \sigma \mathrm{b}^{2}}{\sigma \mathrm{t}^{2}}\right)$

$\mathrm{r}_{11}=$ reabilitas instrumen

$\mathrm{K}=$ banyak butir pertanyaan

$\sigma \mathrm{t}^{2} \quad=$ varian total

$\sum \sigma^{2}=$ jumlah varian butir

Berdasarkan analisis, secara keseluruhan variabel-variabel ini dapat dinyatakan reliabel, karena koefisien alpha lebih besar dari 0,60, maka dapat disimpulkan bahwa seluruh butir-butir pertanyaan reliabel. Dari ke dua hasil analisis reliabilitas di atas dapat diartikan bahwa, secara menyeluruh kuisioner yang digunakan dalam penelitian ini telah dinyatakan reliabel.

Metode analisis yang digunakan adalah Analisis korelasi. Analisis korelasi adalah suatu analisis statistik yang mengukur tingkat asosiasi atau hubungan antara dua variabel, yaitu variabel bebas (independent variable) disimbolkan dengan "X" dan variabel terikat (dependent variable) disimbolkan dengan "Y" disebut korelasi bivariat. Korelasi bermanfaat untuk mengukur kekuatan hubungan antara dua variabel (kadang lebih dari dua variabel) dengan skala-skala tertentu, misalnya Pearson data harus berskala interval atau rasio; Spearman dan Kendal menggunakan skala ordinal; Chi Square menggunakan data nominal. Kuat lemah hubungan diukur diantara jarak (range) 0 sampai dengan 1 . Korelasi mempunyai kemungkinan pengujian hipotesis dua arah (two tailed). Korelasi searah jika nilai koefesien korelasi diketemukan positif; sebaliknya jika nilai koefesien korelasi negatif, korelasi disebut tidak searah. Koefesien korelasi ialah suatu pengukuran statistik kovariasi atau asosiasi antara dua variabel. Jika koefesien korelasi diketemukan tidak sama dengan nol (0), maka terdapat ketergantungan antara dua variabel tersebut. Jika koefesien korelasi diketemukan +1. maka hubungan tersebut disebut sebagai korelasi sempurna atau hubungan linear sempurna dengan kemiringan (slope) positif. Jika koefesien korelasi diketemukan -1. maka hubungan tersebut disebut sebagai korelasi sempurna atau hubungan linear sempurna dengan kemiringan (slope) negatif (Sugiyono, 2003).

\section{Koefisien Korelasi Asosiasi Eta.}

Asosiasi ini digunakan untuk mengetahui besarnya hubungan antara variabel data yang berskala nominal dan interval (Sofyan, Y dan Heri, K, 2009). Untuk menguji hubungan Jenis Kelamin dan Status Perkawinan dengan Aspirasi menggunakan koefisien korelasi Asosiasi Eta, dengan rumus sebagai berikut: $\eta=\sqrt{1-\frac{\left.\sum \mathrm{Y}_{\mathrm{T}}^{2}-\left(\mathrm{N}_{1}\right)\left(\overline{\mathrm{Y}_{1}}\right)^{2}-\left(\mathrm{N}_{1}\right) \overline{\mathrm{Y}}_{2}\right)^{2}}{\sum \mathrm{Y}_{\mathrm{T}}^{2}-\left(\mathrm{N}_{1}+\mathrm{N}_{2}\right) \overline{\mathrm{Y}}_{\mathrm{T}}^{2}}}$

Dimana:

$\mathrm{N}_{1}$ dan $\mathrm{N}_{2}=$ sampel 1 dan sampel 2

*) Mahasiswa Jurusan Manajemen Agribisnis, Politeknik Negeri Jember

**) Staf Pengajar Jurusan Manajemen Agribisnis, Politeknik Negeri Jember 


$$
\begin{aligned}
\mathrm{Y}_{\mathrm{T}} & =\text { rata-rata besar untuk kelompok 1 dan } \\
& 2 \text { digabung } \\
\sum \mathrm{Y}_{\mathrm{T}}^{2} & =\text { jumlah kuadrat kedua buah sampel } \\
\mathrm{Y}_{1} \text { dan } \mathrm{Y}_{2}= & \text { rata-rata tiap kelompok }
\end{aligned}
$$

\section{Koefisien Korelasi Spearman's rho}

Spearman's rho merupakan statistik yang populer digunakan untuk mengukur hubungan antara dua variabel ordinal. Statistik ini, yang merupakan bentuk khusus dari korelasi Pearson's product moment, mengkaitkan ranking 2 buah variabel. Teknik ini juga biasa digunakan untuk skor variabel yang $\rho=1-\frac{6 \sum_{i=1}^{n} d i^{2}}{n\left(n^{2}-1\right)}$

Dimana:

$\begin{array}{ll}\mathrm{d} & =\text { Beda diantara pasangan jenjang (rank) } \\ \mathrm{n} & =\text { Jumlah pasangan jenjang }(\text { rank }) \\ \rho & =\text { Koefisien korelasi Rank Spearman }\end{array}$

\section{Analisis Korelasi Pearson Product Moment}

Korelasi Pearson biasanya pada hubungan yang berbentuk linier (keduanya meningkat atau keduanya menurun). Koefisien korelasi ini tidak menunjukkan adanya hubungan kausal antar

$$
. r_{x y}=\frac{n \sum x y-\left(\sum x\right)\left(\sum y\right)}{\sqrt{\left[\left\{n \sum x^{2}-\left(\sum x\right)^{2}\right\}\left\{n \sum y^{2}-\left(\sum y\right)^{2}\right\}\right]}}
$$

Dimana:

$\mathrm{r}_{\mathrm{xy}} \quad=$ korelasi product moment

$\mathrm{n} \quad=$ jumlah responden

$\mathrm{x} \quad=$ jumlah skor tiap pertanyaan

$\mathrm{y} \quad=$ jumlah skor total

\section{HASIL DAN PEMBAHASAN}

\section{Hasil Analisis}

\section{Hubungan Jenis Kelamin dengan Aspirasi} Berdasarkan dari hasil analisis koefisien korelasi Asosiasi Eta yang telah dilakukan untuk mengukur besarnya koefisien korelasi antara Status Tabel 1 Hasil Analisis Korelasi Asosiasi Eta antara Jenis Kelamin $\left(\mathbf{X}_{1}\right)$ dengan Aspirasi (Y) tadinya interval atau rasio tetapi skor tersebut terlalu banyak ketidak normalannya sehingga skor tersebut diturunkan tingkatannya dalam bentuk urutan nilainya saja dan dihitung nilai spearman's rho-nya (Elearning, 2008). Untuk menguji hubungan Usia dan Tingkat Pendidikan dengan Aspirasi menggunakan koefisien korelasi spearman's rho, dengan rumus sebagai berikut: variabelnya. Untuk menguji hubungan Karakteristik Lingkungan dengan Aspirasi menggunakan analisis Korelasi Pearson Product Moment dengan rumus (Sugiyono, 2003) sebagai berikut
Perkawinan $\left(\mathrm{X}_{2}\right)$ dengan Aspirasi (Y) pada Pemuda yang bekerja di agroindustri perikanan di Desa Puger Wetan, Kecamatan Puger, Kabupaten Jember. Dapat dilihat pada output SPSS sebagai berikut:

\begin{tabular}{lrrr}
\hline & Directional Measures & & Value \\
\hline Nominal by Interval & & & .571 \\
\cline { 3 - 4 } & Eta & Jenis_Kelamin Dependent & .089 \\
\cline { 3 - 4 } & & Aspirasi Dependent &
\end{tabular}

Sumber : Data primer diolah

Berdasarkan output di atas dapat diketahui bahwa terdapat hubungan yang nyata positif antara jenis kelamin dengan aspirasi sebesar 0,571 di tunjukkan pada (tabel 3.5). Artinya bahwa kelompok responden laki-laki lebih tinggi memiliki aspirasi bekerja dalam bidang agroindustri perikanan. 


\section{Hubungan Status Perkawinan dengan Aspirasi}

Berdasarkan dari hasil analisis koefisien korelasi Asosiasi Eta yang telah dilakukan untuk mengukur besarnya koefisien korelasi antara Status Perkawinan
$\left(\mathrm{X}_{2}\right)$ dengan Aspirasi (Y) pada Pemuda yang bekerja di agroindustri perikanan di Desa Puger Wetan, Kecamatan Puger, Kabupaten Jember. Dapat dilihat pada output SPSS sebagai berikut:

Tabel 2 Hasil Analisis Korelasi Asosiasi Eta antara Status Perkawinan $\left(\mathbf{X}_{2}\right)$ dengan Aspirasi (Y)

\section{Directional Measures}

\begin{tabular}{lllr}
\hline & & Value \\
\hline Nominal by Interval & \multirow{2}{*}{ Eta } & Status Perkawinan Dependent & .630 \\
\cline { 3 - 4 } & & Aspirasi Dependent & .117 \\
\hline
\end{tabular}

Sumber : Data primer diolah

Berdasarkan output di atas dapat diketahui bahwa terdapat hubungan yang nyata positif antara status perkawinan dengan aspirasi sebesar 0,630 di tunjukkan pada (tabel 3.5). Artinya bahwa status perkawinan memiliki hubungan dengan aspirasi bekerja dalam bidang agroindustri perikanan.

Hubungan Usia dengan Aspirasi

Tabel 3 Hasil Analisis Korelasi Spearman's rho antara Usia $\left(\mathrm{X}_{3}\right)$ dengan Aspirasi (Y)
Berdasarkan dari hasil analisis koefisien korelasi Spearman's rho yang telah dilakukan untuk mengukur besarnya koefisien korelasi antara Usia $\left(\mathrm{X}_{3}\right)$ dengan Aspirasi (Y) pada Pemuda yang bekerja di agroindustri perikanan di Desa Puger Wetan, Kecamatan Puger, Kabupaten Jember. Dapat dilihat pada output SPSS sebagai berikut:

\begin{tabular}{lllrr}
\hline \multicolumn{5}{c}{ Correlations } \\
\hline & & Usia & \multicolumn{2}{c}{ Aspirasi } \\
\hline Spearman's rho & \multirow{2}{*}{ Usia } & Correlation Coefficient & 1.000 & .205 \\
& & Sig. (2-tailed) &. & .246 \\
& $\mathrm{~N}$ & 34 & 34 \\
\cline { 3 - 5 } & Aspirasi & Correlation Coefficient & .205 & 1.000 \\
& & Sig. (2-tailed) & .246 & 34 \\
& $\mathrm{~N}$ & 34 & \\
& & & &
\end{tabular}

Sumber : Data primer diolah

Berdasarkan output di atas dapat diketahui bahwa koefisien korelasi sebesar 0,205, dari tabel terlihat bahwa untuk $\mathrm{N}=34$ pada taraf kesalahan 5\% diperoleh nilai rho tabel sebesar 0,342 di tunjukkan pada (lampiran 8). Hasil rho hitung ternyata jauh lebih kecil dari nilai rho tabel. Hal ini berarti tidak terdapat hubungan yang nyata antara usia dengan aspirasi. Artinya bahwa, masing-masing usia belum tentu memiliki aspirasi bekerja dalam bidang agroindustri perikanan.

\section{Hubungan Tingkat Pendidikan dengan Aspirasi}

Besdasarkan dari hasil analisis koefisien korelasi Spearman's rho yang telah dilakukan untuk mengukur besarnya koefisien korelasi antara Tingkat Pendidikan $\left(\mathrm{X}_{4}\right)$ dengan Aspirasi (Y) pada Pemuda yang bekerja di agroindustri perikanan di Desa Puger Wetan, Kecamatan Puger, Kabupaten Jember. Dengan output SPSS sebagai berikut:

Tabel 4 Hasil Analisis Korelasi Spearman's rho antara Tingkat $\quad$ Pendidkan ( $\left.\mathrm{X}_{4}\right)$ dengan Aspirasi (Y)

\begin{tabular}{|c|c|c|c|c|}
\hline \multicolumn{5}{|c|}{ Correlations } \\
\hline & & & Tingkat Pendidikan & Aspirasi \\
\hline Spearman's rho & Tingkat & Correlation Coefficient & 1.000 & .132 \\
\hline
\end{tabular}

*) Mahasiswa Jurusan Manajemen Agribisnis, Politeknik Negeri Jember

**) Staf Pengajar Jurusan Manajemen Agribisnis, Politeknik Negeri Jember 


\begin{tabular}{rlrr} 
Pendidikan & Sig. (2-tailed) &. & .458 \\
& $\mathrm{~N}$ & 34 & 34 \\
\hline Aspirasi & Correlation Coefficient & .132 & 1.000 \\
& Sig. (2-tailed) & .458 &. \\
& $\mathrm{~N}$ & 34 & 34 \\
\hline
\end{tabular}

Sumber : Data primer diolah

Berdasarkan output di atas dapat diketahui bahwa koefisien korelasi sebesar 0,132, dari tabel terlihat bahwa untuk $\mathrm{N}=34$ pada taraf kesalahan 5\% diperoleh nilai rho tabel sebesar 0,342 di tunjukkan pada (lampiran 8). Hasil rho hitung ternyata jauh lebih kecil dari nilai rho tabel. Hal ini berarti tidak terdapat hubungan yang nyata antara tingkat pendidikan dengan aspirasi. Artinya bahwa, masing-masing tingkat pendidikan belum tentu memiliki aspirasi bekerja dalam bidang agroindustri perikanan.

Tabel 5 Hasil Analisis Korelasi Pearson Product Moment antara Karakteristik Lingkungan (X) dengan

\begin{tabular}{|c|c|c|c|}
\hline \multicolumn{4}{|c|}{ Correlations } \\
\hline & & Karakteristik_Lingkungan & Aspirasi \\
\hline \multirow[t]{3}{*}{ Karakteristik_Lingkungan } & Pearson Correlation & 1 & $.656^{* *}$ \\
\hline & Sig. (2-tailed) & & .000 \\
\hline & $\mathrm{N}$ & 34 & 34 \\
\hline \multirow[t]{3}{*}{ Aspirasi } & Pearson Correlation & $.656^{* *}$ & 1 \\
\hline & Sig. (2-tailed) & .000 & \\
\hline & $\mathrm{N}$ & 34 & 34 \\
\hline
\end{tabular}

\section{Hubungan Krakteristik Lingkungan dengan Aspirasi}

Berdasarkan dari hasil analisis koefisien korelasi Pearson Product Moment yang telah dilakukan untuk mengukur besarnya koefisien korelasi antara Krakteristik Lingkungan $\left(\mathrm{X}_{5}\right)$ dengan Aspirasi (Y) pada Pemuda yang bekerja di agroindustri perikanan di Desa Puger Wetan, Kecamatan Puger, Kabupaten Jember. Dapat dilihat pada output SPSS sebagai berikut:

\section{Aspirasi (Y)}

Sumber : Data primer diolah

Berdasarkan output di atas dapat diketahui bahwa koefisien korelasi sebesar 0,656, dari tabel terlihat bahwa untuk $\mathrm{N}=34$ pada taraf kesalahan $5 \%$ diperoleh nilai $r$ tabel sebesar 0,339 di tunjukkan pada (lampiran 7). Hasil $r$ hitung ternyata jauh lebih besar dari nilai $r$ tabel. Hal ini berarti terdapat hubungan yang nyata antara karakteristik lingkungan dengan aspirasi. Artinya bahwa, semakin banyak pemuda berinteraksi dengan pelaku usaha yang sukses dan semakin mengikat norma atau aturan yang dibuat pada agroindustri perikanan juga semakin lengkap sarana dan prasarana maka semakin tinggi aspirasi bekerja dalam bidang agroindustri perikanan.

\section{PEMBAHASAN}

Jenis Kelamin Terdapat hubungan yang nyata dengan aspirasi karena dari jenis kelamin laki-laki dan perempuan memiliki aspirasi yang sedang untuk bekerja pada agroindustri perikanan, hal ini disebabkan karena setiap jenis kelamin tidak memiliki batasan untuk bekerja.

Status perkawinan terdapat hubungan yang nyata dengan aspirasi karena pemuda dengan status belum menikah dan menikah memiliki aspirasi yang tinggi untuk bekerja pada agroindustri perikanan hal ini di sebabkan karena mereka belum mempunyai tanggungan dan hanya lebih mementingkan kebutuhan diri sendiri dengan lebih banyak waktu untuk bekerja dan banyaknya kebutuhan dari keluarga yang harus dipenuhi dan semakin besar tanggung jawab mereka sehingga lebih memilih untuk tidak melanjutkan bekerja pada agroindustri perikanan atau pindah mencari pekerjaan lain.

Usia tidak terdapat hubungan yang nyata dengan aspirasi karena semakin tinggi usia maka belum tentu semakin tinggi atau semakin rendah aspirasi dalam bekerja pada agroindustri perikanan, 
juga semakin rendah usia maka belum tentu semakin tinggi atau semakin rendah aspirasi dalam bekerja pada agroindustri perikanan. Hal ini disebabkan, tidak selalu pemuda yang masih dalam masa pertumbuhan (15-17 tahun) dan pertengahan (18-20 tahun) memiliki aspirasi dan sebaliknya tidak selalu masa pemuda akhir (21-24 tahun) memiliki aspirasi untuk bekerja dalam bidang agroindustri perikanan.

Tingkat pendidikan tidak terdapat hubungan yang nyata dengan aspirasi karena semakin tinggi tingkat pendidikan maka belum tentu semakin tinggi atau semakin rendah pula aspirasi dalam bekerja dalam bidang agroindustri perikanan, juga semakin rendah tingkat pendidikan maka belum tentu semakin tinggi atau semakin rendah aspirasi bekerja dalam bidang agroindustri perikanan. Hal ini disebabkan, pemuda yang pendidikannya lebih tinggi cenderung gengsi untuk bekerja pada agroindustri perikanan, mereka lebih memilih untuk bekerja selain bidang agroindustri perikanan. Ilmu pengetahuan terhadap agroindustri perikanan tidak dipelajari secara langsung di bangku sekolah tetapi pada umumnya diperoleh langsung dari pengalaman sehingga tidak menimbulkan aspirasi bekerja dalam bidang agroindustri perikanan.

Karakteristik lingkungan terdapat hubungan yang nyata dengan aspirasi karena dari pelaku usaha yang sukses akan mempengaruhi daya psikis pemuda sehingga bila pemuda sering berinterkasi maka sedikit demi sedikit keinginan pemuda untuk mencontoh pelaku usaha yang suskses tersebut.

Kelembagaan sosial pada pemuda merupakan norma yang dibuat pada suatu agroindustri perikanan yang mengikat dan aturan dilakukan secara tegas, jelas dan konsekuen. Pembuatan norma di agroindustri perikanan mempunyai tujuan agar pemuda mempunyai kedisiplinan kerja, maka semakin tinggi aspirasi bekerja dalam bidang agroindustri perikanan.

Sarana dan prasarana yang lengkap dan modern melancarkan cara berfikir pemuda untuk menumbuhkan aspirasi dalam bekerja pada agroindustri perikanan. Sedangkan aspirasi pemuda di daerah agroindustri perikanan puger wetan dapat lebih berkembang dengan adanya sarana dan prasarana yang mendukung dengan teknologi modern tersebut untuk meningkatkan kualitas agroindustri perikanan melalui penerapan teknologi tepat guna dan memberikan ketrampilan kepada industri tradisional tentang teknologi yang lebih sanitier dan hygiene, aman pangan baik konsumen serta melalui pelatihan dan demontrasi. Selain itu, bertujuan pula untuk meningkatkan pendapatan pengolah ikan dengan terdapatnya nilai tambah pada ikan setelah diproses maka harga jualnya lebih tinggi dari ketika masih segar. Disamping itu kemungkinan dipergunakan untuk diversifikasi usaha lain.

\section{KESIMPULAN}

Berdasarkan pembahasan yang telah diuraikan mengenai hasil analisis dapat diperoleh kesimpulan sebagai berikut :

1. Secara umum terdapat hubungan antara karakteristik individu dengan aspirasi meliputi:

a. Terdapat hubungan yang nyata positif antara jenis kelamin dengan aspirasi.

b. Terdapat hubungan yang nyata positif antara status perkawinan dengan aspirasi.

c. Tidak terdapat hubungan yang nyata antara usia dengan aspirasi.

d. Tidak terdapat hubungan yang nyata antara tingkat pendidikan dengan aspirasi.

2. Terdapat hubungan yang nyata positif antara karakteristik lingkungan dengan aspirasi.

\section{DAFTAR PUSTAKA}

Anonim. 2008. Prospek agroindustri terasi dan kontribusinya Terhadap pendapatan keluarga nelayan. http//:digilib.unej.ac.id. di akses tanggal 24 mei 2009.

Arikunto, S. 2006. Prosedur Penelitian Suatu Pendekatan Praktik. Jakarta: Rineka Cipta.

Gujarati, D. 1995, Analisis Korelasi dan Asosiasi. http://susenobimo.blogspot.com.html. di akses tanggal 5 mei 2009.

I Nyoman Suarta. 2003. Hubungan Tingkat Aspirasi Pendidikan dan Pekerjaan Pada Remaja dengan Harapan Orangtua Terhadap Pendidikan dan Pekerjaan Anak. Universitas Indonesia. http://www.lontar.ui.ac.id diakses tanggal 10 Desember 2009.

Moloeng. 2002. Metodologi penelitian kualitatif edisi revisi. PT Remaja Rosdakarya, Jakarta.

Pemerintah Kabupaten Jember. 2008. perikanan dan kelautan. http://pemkab jember.com/perikanan dan kelautan. di akses tanggal 2 mei 2009.

\section{*) Mahasiswa Jurusan Manajemen Agribisnis, Politeknik Negeri Jember}


Jurnal Ilmiah INOVASI, Vol.13 No.2, Hal. 112-120, Mei-Agustus 2013, ISSN 1411-5549

Rahayu, S. 2004. Faktor-Faktor yang Berhubungan dengan Minat Pemuda Pemudi Desa Bekerja di Sektor Perikanan. Lampung Selatan : Jurusan Sosial Ekonomi Pertanian Fakultas Pertanian. dalam Kumpulan Tesis dan Skripsi Pendidikan. $\quad \underline{\text { http://ilmiah- }}$ pendidikan.blogspot.com /2009/11/ pengaruhpendidikan- pelatihan-dan.html. diakses tanggal 10 Desember 2009.

Singarimbun, M dan S. Effendi (Ed). 1995. Metode Penelitian Survai. Jakarta : Pustaka LP3ES Indonesia.
Soemarno, M.S. 2003. Model Pengembangan Lingkungan Pesisir-Pantai. http://images.soemarno.multiply.com. di akses tgl 5 mei 2009.

Soerjono Soekanto. 2007. Sosiologi Suatu Pengantar. Jakarta: Rajawali.

Sugiyono. 2003. Metode Penelitian Administrasi. Bandung : Alfabeta.

Umar, H. 2002. Metode Riset Bisnis. Penerbit PT Gramedia Pustaka Utama. Jakarta. 